\title{
The effect of the phenylene linkage in poly(fluorene-alt-phenylene)s on the thermodynamics and kinetics of nitroaromatic and nitroaliphatic sensing
}

\author{
George Vamvounis ${ }^{\mathrm{a}, *}$, Marina Fuhrer ${ }^{\mathrm{a}}$, Kevin Keller ${ }^{\mathrm{a}}$, Lukas Willig ${ }^{\mathrm{c}}$, Ami Koizumi ${ }^{\mathrm{a}}$, \\ Hsuan-Ming $\mathrm{Hu}^{\mathrm{a}}$, Mei Gao ${ }^{\mathrm{b}}$, Toby D.M. Bell ${ }^{\mathrm{c}}$ \\ ${ }^{a}$ College of Science and Engineering, James Cook University, Townsville, Queensland 4811, Australia \\ ${ }^{\mathrm{b}}$ Flexible Electronics Laboratory, CSIRO Manufacturing, Clayton, Victoria 3168, Australia \\ ${ }^{\text {c } S c h o o l ~ o f ~ C h e m i s t r y, ~ M o n a s h ~ U n i v e r s i t y, ~ V i c t o r i a ~} 3800$ Australia
}

\section{A R T I C L E I N F O}

\section{Keywords:}

Conjugated polymers

Fluorescence quenching

Nitroaromatic sensing

Nitroaliphatic sensing

\begin{abstract}
A B S T R A C T
The preparation, photophysical characterization and sensing of a series of highly luminescent poly(fluorene-altphenylene)s (PFP) were studied. These PFP polymers varied the phenylene linkage in the 1,4 (PFP-p), 1,3 (PFP$\mathrm{m}$ ) and 1,2 (PFP-o) positions. The photoluminescence of these polymers ranged from ultraviolet to blue in color in both solution and film states by simply varying the linkage of the phenylene moiety. Photon Electron Spectroscopy in Air (PESA) revealed that the change in the emission was primarily attributed to the difference of the electron affinity of the polymer. Stern-Volmer quenching studies indicated that these poly(fluorene-altphenylene) polymers are highly sensitive towards nitroaromatic materials in solution, particularly in comparison to the reference poly(9,9-di- $n$-hexylflourene) (PDHF). These PFP polymers were found to be four to ten times more sensitive towards dinitrobenzene as compared to PDHF. In addition, PFP-o displayed the highest polymerbased Stern-Volmer quenching towards the taggant DMNB. The solid-state fluorescence quenching of the PFP-p and PFP-m films using DMNB was enhanced (up to 71.5\%) compared to the reference PDHF (59.6\%) and was attributed to both thermodynamic and diffusion kinetic factors.
\end{abstract}

\section{Introduction}

Global security is becoming an ever increasing issue and the discovery of new sensing materials that are highly sensitive and selective towards nitroaromatic and nitroaliphatic compounds are needed. There are several sensing strategies that exploit colourimetric [1,2], light scattering [3], electrochemical [4] and fluorescence detection [5-14] technology for this purpose. Of these technologies, fluorescence quenching has been one of the more popular techniques with portable products like Fido on the market today. The enhancement of the selectivity and sensitivity can be achieved through the precise control of the electron affinity (controlling the photoinduced electron transfer) and the molecular free volume (controlling the kinetics of analyte diffusion) of the fluorescent films $[6,7,13,15,16]$. In this work, the electron affinity and the porosity of fluorene-alt-phenylene polymers are controlled using various types of phenylene linkages for the sensing of nitroaromatic and nitroaliphatic analytes.

Fluorescence quenching can be achieved using fluorescent small molecules [10,11], dendrimers [9,16-19], quantum dots [20], metalorganic frameworks [21] and polymers [6-8,12,13]. Polymeric materials has driven this area of research because of the amplification of fluorescence quenching that occurs through the influence of one quencher within the entire multi-fluorophore polymeric chain $[6,7]$. Iptycene containing poly(phenylene-ethynylene)s are one of the leading materials used for explosives detection because of their appropriate electron affinity, allowing efficient photoinduced electron transfer, and low packing density, allowing penetration of the analyte [22]. Although these classes of polymers demonstrate high sensitivity towards nitroaromatic compounds, they are limited in terms of nitroaliphatic analytes which are used as taggants or accelerants $[18,23]$. To address this, polymers based on fluorene-alt-phenylene have had promising quenching properties for nitroaliphatic compounds. In addition, these polymers are fairly easy to prepare via a typical Suzuki step-growth polymerization which is tolerant to a wide variety of functional groups, meaning a plethora of materials can be obtained [23,24]. For instance, Swagger and coworkers have prepared a dioctylamine- or dioctyloxyfunctionalized poly(fluorene-alt-phenylene)s and have shown the highest polymer-based DMNB sensitivity [23]. To that end, these polymers exhibited a Stern-Volmer quenching constant of up to $22 \mathrm{M}^{-1}$ and solid state quenching of $20 \%$ using a Nemadics Fido sensor device

\footnotetext{
* Corresponding author.

E-mail address: george.vamvounis@jcu.edu.au (G. Vamvounis).
} 
[23]. It was found that the dioctyloxy functionalized poly(fluorene-altphenylene) had a good balance of the thermodynamic requirement for photoinduced electron transfer, diffusion quenching kinetics (governed by electrostatic attraction and exciton mobility) for DMNB sensing. However, these polymers showed a higher response to a potential false positive, benzophenone [23].

In an effort to improve the selectivity and sensitivity of polymer sensors, fine tuning of both the porosity of the polymer and the thermodynamic requirements for photoinduced electron transfer is needed. One method to vary the molecular free volume in polymers is by varying the isomer of a di-functional comonomer using step-growth polymerisation. To that end, poly(fluorene-alt-thiophene)s were prepared that varied the dibromothiphene isomer, which resulted in "kinked" polymer backbones [25-27]. These polymers may vary the free molecular volume, but the sulfur in the thiophene units can promote intersystem crossing via spin-orbit coupling and may limit collisional quenching of the photoluminescence. Here, we present the synthesis of a series of poly(fluorene-alt-phenylene)s with different phenylene linkages to determine the role of the phenylene linkage on the polymer's electron affinity and analyte diffusion for nitroaromatic and aliphatic sensing (Fig. 1).

\section{Experimental part}

\subsection{Materials}

9,9-Di-n-hexyl-9H-fluorene-2,7-diboronic acid (Boron Molecular), 9,9-di-n-hexyl-2,7-dibromofluorene (Boron Molecular), 1,4-diiodobenzene (Matrix Scientific), 1,3-diiodobenzene (Matrix Scientific), 1,2diiodobenzene (Matrix Scientific), tetrakis(triphenylphosphine) palladium (0) (Sigma Aldrich), potassium carbonate (Univar), toluene (Univar), methanol (Univar), tetrahydrofuran (Unichrome), chloroform (Fisher Scientific), Celite (Sigma), quinine sulfate (Sigma Aldrich) and $0.1 \mathrm{M}$ sulfuric acid (Univol) were used as received.

\subsection{Characterization}

${ }^{1} \mathrm{H}$ NMR spectra were recorded on a Bruker Ascend ${ }^{\mathrm{TM}} 400 \mathrm{MHz}$ spectrometer. Chemical shifts are reported in parts per million (ppm) and are referenced to the residual solvent peak (chloroform, $\left.{ }^{1} \mathrm{H}=7.26 \mathrm{ppm}\right)$. Coupling constants $(J)$ are quoted in Hertz $(\mathrm{Hz})$ and quoted to the nearest $0.5 \mathrm{~Hz}$. Peak multiplicities are described in the following manner: doublet (d), quintet (quin), doublet of doublets (dd), multiplet (m). The polymer molecular weights were estimated using gel permeation chromatography (Agilent Technologies 1260 Infinity Series) equipped with a UV absorption and refractive index detector. The PLgel $5 \mu \mathrm{m}$ Mixed-C columns $(300 \times 7.5 \mathrm{~mm}) \times 2$ were calibrated using polystyrene narrow standards in tetrahydrofuran. Infrared spectra of the neat materials were recorded using a Nicolet 6700 FT-IR spectrometer equipped with an attenuated total reflection (ATR) crystal. Absorption spectra were recorded using a Shimadzu UV1800 spectrophotometer and emission spectra were measured using a Perkin Elmer LS50B spectrometer. Solution photoluminescence quantum yields $\left(\Phi_{\mathrm{p} 1}\right)$ were measured by a relative method using quinine sulfate in $0.1 \mathrm{M}$ sulphuric acid as the standard, which has a photoluminescence quantum yield of $0.55[28,29]$. The excitation and emission slit widths were both set to $6 \mathrm{~nm}$. The optical densities of the standard and sample were between 0.1 and 0.05 at the excitation wavelength. The refractive indices of the tetrahydrofuran and the sulphuric acid solution were 1.404 and 1.334, respectively. The error of these measurements is estimated to be less than $\pm 5 \%$ of the reported value. Data corresponding to these measurements are given in the Supporting Information. Thin films for measuring UV-Vis absorption and emission spectra were prepared on glass (Sail Brand) for PDHF, PFP-p and PFP-m, and quartz (Aireka Scientific) for PFP-o by spin coating $7.5 \mathrm{mg} / \mathrm{mL}$ (toluene) solution at 1500 rotations per minute for $60 \mathrm{~s}$ using a Chemat KW-4A spin coater. The emission spectra were recorded at a scan rate of $2 \mathrm{~nm} / \mathrm{sec}$ with an incidence angle of $45^{\circ}$ and the slit widths were set to $10 \mathrm{~nm}$.

Ionization potentials were determined using photoelectron spectroscopy in air (PESA) using a light intensity of $10-20 \mathrm{nW}$ with a Riken Keiki AC-2 spectrometer. The electron affinity was estimated using the linear combination of the ionization potential and the lowest energy maximum absorption. The diameter of the analytes were estimated using a semi-empirical AM1 calculation (HyperChem 8.0). The surface morphology and thickness was measured using an NTEGRA TS-150 atomic force microscope.

\subsection{Synthesis}

PFP-p: A $50 \mathrm{~mL}$ Schlenk tube was charged with 1,4-diiodobenzene ( $0.113 \mathrm{~g}, 0.341 \mathrm{mmol}), 9,9-\mathrm{di}-n$-hexyl-9H-fluorene-2,7-diboronic acid $(0.200 \mathrm{~g}, 0.341 \mathrm{mmol})$, tetrakis(triphenylphosphine) palladium (0) $\left(0.005 \mathrm{~g}, 4.3 \times 10^{-6} \mathrm{~mol}\right)$ in toluene $(3.5 \mathrm{~mL})$ and aqueous potassium carbonate $(2 \mathrm{M}, 2 \mathrm{~mL})$. This solution was degassed with three freezepumpthaw cycles and covered with a blanket of argon. This solution was stirred at $100{ }^{\circ} \mathrm{C}$ for $88 \mathrm{~h}$. The reaction was quenched with $25 \mathrm{~mL}$ of water, and the mixture was extracted with chloroform $(3 \times 50 \mathrm{~mL})$. The combined layers were washed with water $(2 \times 50 \mathrm{~mL})$ and brine $25 \mathrm{~mL}$. The organic layer was dried over anhydrous sodium sulfate, filtered through Celite and the solvent was removed under reduced pressure to roughly $2 \mathrm{~mL}$. The polymer was precipitated into methanol $(50 \mathrm{~mL})$ to afford a pale yellow solid ( $0.068 \mathrm{~g}, 49 \%)$. GPC: $\mathrm{M}_{\mathrm{n}}=23,300, \mathrm{M}_{\mathrm{w}}=87$, $400, \mathrm{PDI}=3.75 ; \lambda_{\max }$ (toluene) $/ \mathrm{nm} \mathrm{371;} v_{\max }$ (neat) $/ \mathrm{cm}^{-1} 3019$, 2952, 2925, 2855, 1460,1404, 1376, 1248, 1012, 810, 745, 724; ${ }^{1} \mathrm{H}$ NMR $\left(400 \mathrm{MHz}, \mathrm{CDCl}_{3}\right) \delta: 0.77-0.81(10 \mathrm{H}, \mathrm{m}), 1.11-1.16(12 \mathrm{H}, \mathrm{m})$, 2.09 (4H, m), 7.66-7.85 (10H, m).

PFP-m: A $50 \mathrm{~mL}$ Schlenk tube was charged with 1,3-diiodobenzene $(0.113 \mathrm{~g}, 0.341 \mathrm{mmol}), 9,9-\mathrm{di}-n$-hexyl-9H-fluorene-2,7-diboronic acid $(0.200 \mathrm{~g}, 0.341 \mathrm{mmol})$, tetrakis(triphenylphosphine) palladium (0) $\left(0.010 \mathrm{~g}, 8.6 \times 10^{-6} \mathrm{~mol}\right)$ in toluene $(3.5 \mathrm{~mL})$ and aqueous potassium carbonate $(2 \mathrm{M}, 2 \mathrm{~mL})$. This solution was degassed with three freezepumpthaw cycles and covered with a blanket of argon. This solution was stirred at $100{ }^{\circ} \mathrm{C}$ for $88 \mathrm{~h}$. The reaction was quenched with $25 \mathrm{~mL}$ of water, and the mixture was extracted with chloroform $(3 \times 50 \mathrm{~mL})$. The combined layers were washed with water $(2 \times 50 \mathrm{~mL})$ and brine $25 \mathrm{~mL}$. The organic layer was dried over anhydrous sodium sulfate, filtered

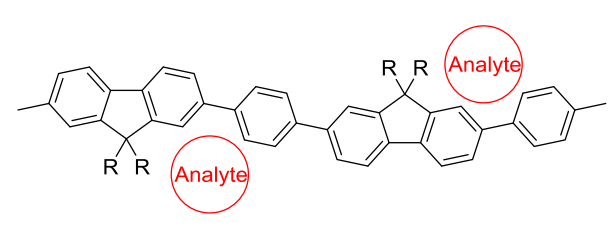

PFP-p

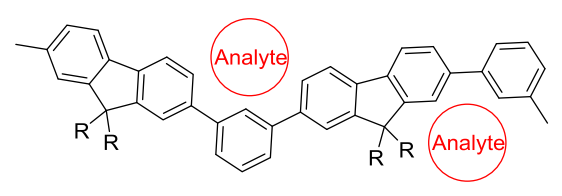

PFP-m

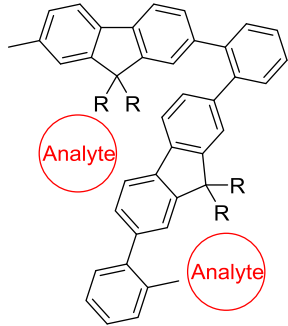

PFP-O

Fig. 1. Two-dimensional view of PFP mimics using two repeat units with potential voids where analytes (scaled to a nitroaromatic) could occupy. 
<smiles>CCCCCCCCCCCCCCCCCCC1(CCCCCCC)c2cc(I)ccc2-c2ccc(B3OC(C)(C)C(C)(C)O3)cc21</smiles><smiles>CC1(C)OBOC1(C)C</smiles><smiles>Ic1ccc(I)cc1</smiles>

or<smiles>Ic1cccc(I)c1</smiles><smiles>CC#CC</smiles>

or<smiles>CCCCCC(C)(C)c1ccc2c(c1)C(C)(C)c1cc(-c3ccc(C(C)(C)C)cc3)ccc1-2</smiles>

PFP-p<smiles>Ic1ccccc1I</smiles><smiles>CC#CC</smiles><smiles>CCCCCCC1(CCCCC)c2cc(C)ccc2-c2ccc(-c3ccccc3C)cc21</smiles>

PFP-O<smiles>CCCCCC1(CCCCC)c2cc(Br)ccc2-c2ccc(Br)cc21</smiles><smiles>CCCCCC1(C)c2cc(C(C)(C)C)ccc2-c2ccc(C(C)(C)C)cc21</smiles>

Scheme 1. Synthesis of poly(fluorene-alt-phenylene)s and poly(9,9-di-n-hexylfluorene). Reagents and conditions: $2 \mathrm{M}$ potassium carbonate (aq), $\mathrm{Pd}\left(\mathrm{PPh}_{3}\right)_{4}, 100{ }^{\circ} \mathrm{C}$, Ar, toluene (i, ii) or tetrahydrofuran (iii, iv), 88 to $144 \mathrm{~h}$.

Table 1

Summary of PFP-p, PFP-m, PFP-o and PDHF absorption and emission spectral data (sh represents shoulder).

\begin{tabular}{|c|c|c|c|c|c|c|}
\hline Polymer & $\begin{array}{l}\lambda_{\max } \\
\text { Absorban } \\
\text { Solution } \mathrm{f}\end{array}$ & & $\begin{array}{l}\lambda_{\max } \\
\text { Emission/nm } \\
\text { Solution film }\end{array}$ & & $\begin{array}{l}\tau_{\mathrm{PL}} / \mathrm{ns} \\
\text { Solution }\end{array}$ & $\Phi_{\mathrm{PL}}$ \\
\hline PFP-p & 371 & 373 & $410,434,470(\mathrm{sh})$ & $421,443,480(\mathrm{sh}), 522(\mathrm{sh})$ & 0.4 & 0.87 \\
\hline PFP-o & 298,323 & 300,325 & $387(\mathrm{sh}), 408,433(\mathrm{sh})$ & $414,451(\mathrm{sh})$ & 0.8 & 0.67 \\
\hline PDHF & 381 & 382 & $415,439,470(\mathrm{sh})$ & $426,448,482(\mathrm{sh})$ & 0.4 & 0.74 \\
\hline
\end{tabular}

through Celite and the solvent was removed under reduced pressure to roughly $2 \mathrm{~mL}$. The polymer was precipitated into methanol $(50 \mathrm{~mL})$ to afford a pale yellow solid $(0.055 \mathrm{~g}, 40 \%)$. GPC: $\mathrm{M}_{\mathrm{n}}=6700$, $\mathrm{M}_{\mathrm{w}}=19,200, \mathrm{PDI}=2.9 ; \lambda_{\max }$ (toluene) $/ \mathrm{nm} 339 ; v_{\max }$ (neat) $/ \mathrm{cm}^{-1}$ 3053, 2926, 2855, 1608, 1458, 1351, 1308, 1144, 963, 850, 826, 792; ${ }^{1} \mathrm{H}$ NMR (400 MHz, $\left.\mathrm{CDCl}_{3}\right)$ 8: $0.77(10 \mathrm{H}, \mathrm{m}), 1.10(12 \mathrm{H}, \mathrm{m}), 2.08(4 \mathrm{H}$, $\mathrm{m}), 7.56-7.97(10 \mathrm{H}, \mathrm{m})$.

PFP-o: A $50 \mathrm{~mL}$ Schlenk tube was charged with 1,2-diiodobenzene $(0.113 \mathrm{~g}, 0.341 \mathrm{mmol}), 9,9-$ di-n-hexyl-9H-fluorene-2,7-diboronic acid $(0.200 \mathrm{~g}, 0.341 \mathrm{mmol})$, tetrakis(triphenylphosphine) palladium (0) $\left(0.009 \mathrm{~g}, 7.7 \times 10^{-6} \mathrm{~mol}\right)$ in tetrahydrofuran $(3.5 \mathrm{~mL})$ and aqueous potassium carbonate $(2 \mathrm{M}, 2 \mathrm{~mL})$. This solution was degassed with three freeze-pumpthaw cycles and covered with a blanket of argon. This solution was stirred at $85^{\circ} \mathrm{C}$ for $144 \mathrm{~h}$. The reaction was quenched with $25 \mathrm{~mL}$ of water, and the mixture was extracted with chloroform $(3 \times 50 \mathrm{~mL})$. The combined layers were washed with water $(2 \times 50 \mathrm{~mL})$ and brine $25 \mathrm{~mL}$. The organic layer was dried over anhydrous sodium sulfate, filtered through Celite and the solvent was removed under reduced pressure to roughly $2 \mathrm{~mL}$. The polymer was precipitated into methanol $(50 \mathrm{~mL})$ to afford a white solid $(0.120 \mathrm{~g}$, 86\%). GPC: $\mathrm{M}_{\mathrm{n}}=1300, \mathrm{M}_{\mathrm{w}}=1800$, PDI $=1.4 ; \lambda_{\max }$ (toluene) $/ \mathrm{nm}$ 298,$323 ; v_{\max }$ (neat) $/ \mathrm{cm}^{-1} 2926,2855,1598,1460,1411,1354$, 1248, 1144, 1028, 892, 822, 725, 696; ${ }^{1} \mathrm{H}$ NMR (400 MHz, $\mathrm{CDCl}_{3}$ ) $\delta$ : 0.48-1.40 (22H, m), 1.62-2.03 (4H, m), 7.02-7.99 (10H, m).

PDHF: A $25 \mathrm{~mL}$ Schlenk tube was charged with 9,9-di- $n$-hexyl-2,7dibromofluorene $(0.420 \mathrm{~g}, 0.8525 \mathrm{mmol}), 9,9$-di- $n$-hexyl-9H-fluorene- 2,7-diboronic acid $(0.500 \mathrm{~g}, 0.8525 \mathrm{mmol})$, tetrakis(triphenylphosphine) palladium (0) $\left(0.030 \mathrm{~g}, 2.6 \times 10^{-5} \mathrm{~mol}\right)$ in tetrahydrofuran $(10 \mathrm{~mL})$ and aqueous potassium carbonate $(2 \mathrm{M}, 6 \mathrm{~mL})$. This solution was degassed with three freeze-pumpthaw cycles and covered with a blanket of argon. This solution was stirred at $85^{\circ} \mathrm{C}$ for $72 \mathrm{~h}$. The reaction was quenched with $25 \mathrm{~mL}$ of water, and the mixture was extracted with chloroform $(3 \times 50 \mathrm{~mL})$. The combined layers were washed with water $(2 \times 50 \mathrm{~mL})$ and brine $25 \mathrm{~mL}$. The organic layer was dried over anhydrous sodium sulfate, filtered through Celite and the solvent was removed under reduced pressure to roughly $4 \mathrm{~mL}$. The polymer was precipitated into methanol $(75 \mathrm{~mL})$ to afford a pale yellow solid $(0.480 \mathrm{~g}, 84 \%)$. GPC THF/Da: $\mathrm{M}_{\mathrm{n}}=6200, \mathrm{M}_{\mathrm{w}}=13,300$, PDI $=2.2$; $\lambda_{\max }$ (toluene)/nm 381; $v_{\max }$ (neat) $/ \mathrm{cm}^{-1} 2925,2854,1456,1376$, 1250, 1134, 999, 884, 812, 740, 722; ${ }^{1} \mathrm{H}$ NMR (400 MHz, $\left.\mathrm{CDCl}_{3}\right) \delta$ : 0.76-0.81 (10H, m), 1.09-1.21 (12H, m), $2.12(4 \mathrm{H}, \mathrm{m}), 7.63-7.71(4 \mathrm{H}$, m), 7.80-7.85 (2H, m).

\subsection{Quenching}

The photoluminescence quenching experiments were measured in toluene and reported as an average of five measurements and each measurement consisted of five analyte concentrations with an $R^{2}$ value of 0.99 or greater. The excitation wavelength was $330 \mathrm{~nm}$ for PFP-o and PFP-m and $350 \mathrm{~nm}$ for PFP-p and PDHF. The excitation and emission slit widths were set at $5 \mathrm{~nm}$. The emission spectra were corrected for inner filter and absorbance of the analyte. The solution data were 

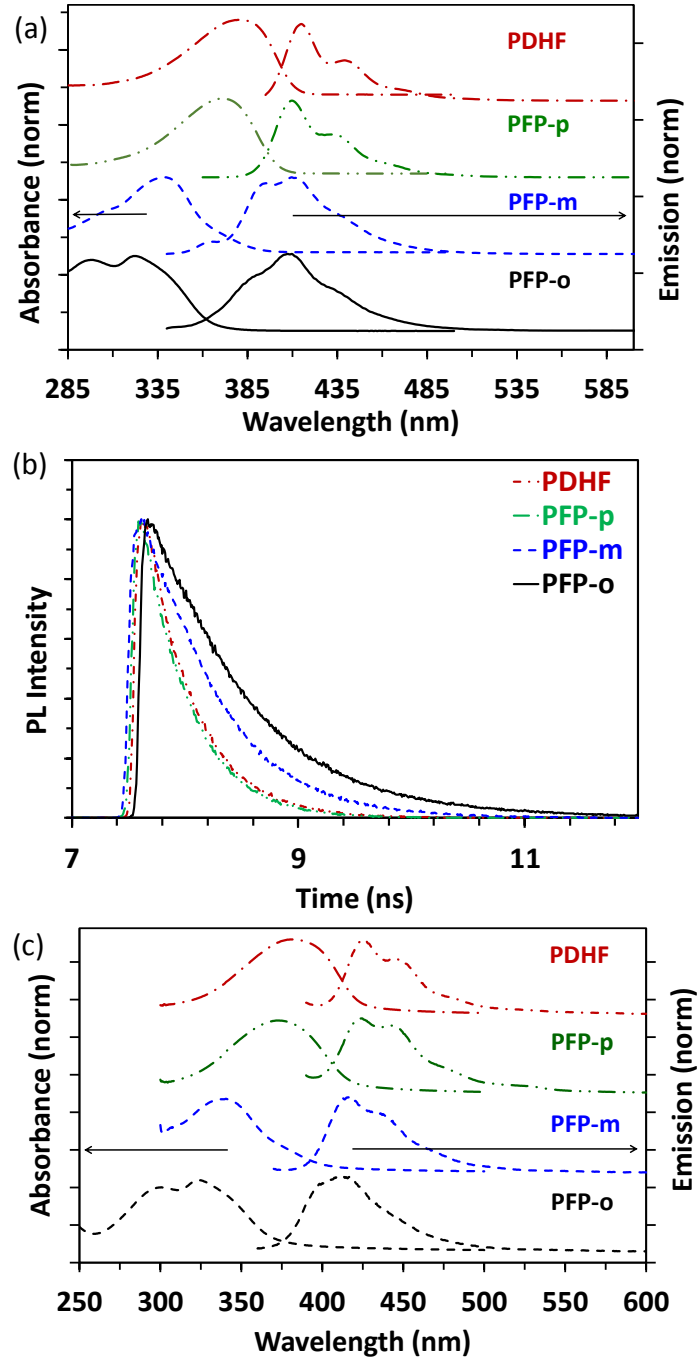

Fig. 2. Absorption and emission of PDHF (red, dash +1 dot), PFP-p (green, dash +2 dots), PFP-m (blue, dashed) and PFP-o (black, solid line) in toluene (a), time resolved measurements in THF (b), and thin film state (c). (For interpretation of the references to color in this figure legend, the reader is referred to the web version of this article.)

collected on a Shimadzu UV1800 UV-Vis absorption spectrometer and a Perkin Elmer LS50B. The films were prepared freshly on a glass substrate by spin coating a $10 \mathrm{mg} / \mathrm{mL}$ polymer solution (chloroform) at $1500 \mathrm{RPM}$ resulting in $105 \pm 10 \mathrm{~nm}$ thick films. The films were dried under vacuum for $1 \mathrm{~h}$ before measurement. The cuvette cells were under a flow of nitrogen at $1 \mathrm{~mL} / \mathrm{min}$. The analyte was introduced into the cell by flowing nitrogen over the analyte at the same rate. The solidstate fluorescence quenching data was collected at an incidence angle of $90^{\circ}$ to avoid reflection. The films were excited at $330 \mathrm{~nm}$ and the emission intensity was measured at $420 \mathrm{~nm}$ for all samples. The film data was collected on a Shimadzu RF6000 spectrofluorimeter.

Time resolved measurements were obtained using a home-built time correlated single photon counting (TCSPC) setup described previously [30]. In short, excitation was provided by a $375 \mathrm{~nm}$ pulsed diode laser (Picoquant, LDH-P-C-375), with emission being passed through a $1 / 4$ wave plate set to the magic angle $\left(54.7^{\circ}\right)$ and monochromator (CVI, $\mathrm{dk480}$ ) prior to being focused onto a microchannel plate (Hamamatsu R3809U-50). Time resolved data were recorded and histogrammed by a photon counting device (Picoquant, PicoHarp 300) with a bin resolution of $8 \mathrm{ps}$. An instrument response function (IRF, typically $\sim 80-100$ ps, FWHM) was obtained by scattering laser light from a dilute milk powder solution in water. Fluorescence lifetimes were calculated by fitting decay histograms by a convolution of the IRF and exponential decay components using an iterative least-squares method based on the Levenberg-Marquardt algorithm using a home-written routine. The goodness of fit was determined from the $\chi^{2}$ value and by inspection of the residuals (data minus fitted function). For all polymers, two exponential decay components were required to achieve a satisfactory fit. Fitted functions comprised a minor short-lived $(<100 \mathrm{ps})$ component and a major, longer-lived component of $100 \mathrm{~s}$ of ps with this latter component contributing $>80 \%$ of the initial decay amplitude in all cases. Similar behaviour was observed for polyfluorene based polymers which are structurally closely related [31]. Longer components are reported and discussed herein with full fitting details in the SI.

\section{Results and discussion}

\subsection{Synthesis}

The synthesis of fluorene-alt-phenylene copolymers were prepared using a Suzuki step-growth polymerization with a diiodobenzene and 9,9-di-n-hexyl-9H-fluorene-2,7-diboronic acid, pinacol ester (Scheme 1). In addition to the PFP copolymers, poly(9, 9-dihexyl fluorenyl-2, 7diyl) (PDHF) was prepared to benchmark our results with a standard phenylene based polymer. The synthetic yields of the polymers ranged from 40 to $86 \%$ and the resultant polymers were soluble in chloroform, tetrahydrofuran and toluene. The molecular weight of PFT-o was low and resembled more of an oligomer however it formed fluorescent uniform films required for this study.

\subsection{Photophysical properties}

The absorbance and photoluminescence properties are summarized in Table 1. The absorption maxima of the polymers in THF are blue shifted from PDHF, PFP-p, PFP-m to PFP-o (Fig. 2a). This trend rationalized by the different effective conjugation length of the various phenyl-fluorenyl linkages. The emission spectra of the polymers in THF were structured and followed the same trend. Quantum yields of photoluminescence $\left(\Phi_{\mathrm{PL}}\right)$ were measured using secondary standard methods, with quinine sulfate in $0.1 \mathrm{M} \mathrm{H}_{2} \mathrm{SO}_{4}$ as the standard $\left(\Phi_{\mathrm{PL}}=0.54\right)[28,29]$. The photoluminescence intensities directly correlated with optical densities of the fluorophores and crossed the origin (see Supporting Information). The $\Phi_{\mathrm{PL}}$ of PDHF was determined to be 0.74 , which is consistent with an absolute method [27]. The $\Phi_{\mathrm{PL}}$ of PFP$\mathrm{p}$ and PFP-m increased to 0.87 and 0.95 , respectively. However, the $\Phi_{\mathrm{PL}}$ of PFP-o was lower at 0.67 . This trend implies that non-radiative pathways due to variations in structural rigidity govern the quantum yield of photoluminescence. The time-resolved photoluminescent data for the polymers range from 0.4 to $0.8 \mathrm{~ns}$ (Fig. 2b), which required fitting with two exponential decay components. This data is consistent to that previously reported on fluorene-based polymers [31]. Fig. 2c depicts the thin film absorption and emission traces of the polymers. The polymers' absorption and emission data follow the same trend as in solution. In comparison to the solution, the spectra are broader and the emission traces are structured. The emission of these polymers was found to be stable over time, with little to no decrease in the intensity of the emission over $30 \mathrm{~min}$ at constant irradiation with $330 \mathrm{~nm}$ light.

\subsection{Sensing}

The fluorescence quenching of three nitroaromatics, namely 4-nitrotoluene (pNT), 2,4-dinitrotoluene (DNT) and 1,4-dinitrobenzene (DNB) were analysed. In addition, explosives taggant 2,3-dimethyl-2,3dinitrobutane (DMNB) and a potential false positive benzophenone (BP) were analysed. The quenching efficiency of PFP-p, PFP-m, PFP-o and PDHF were compared under steady-state conditions by determining the Stern-Volmer quenching constant $\left(K_{S V}\right)$. The Stern-Volmer relationship 

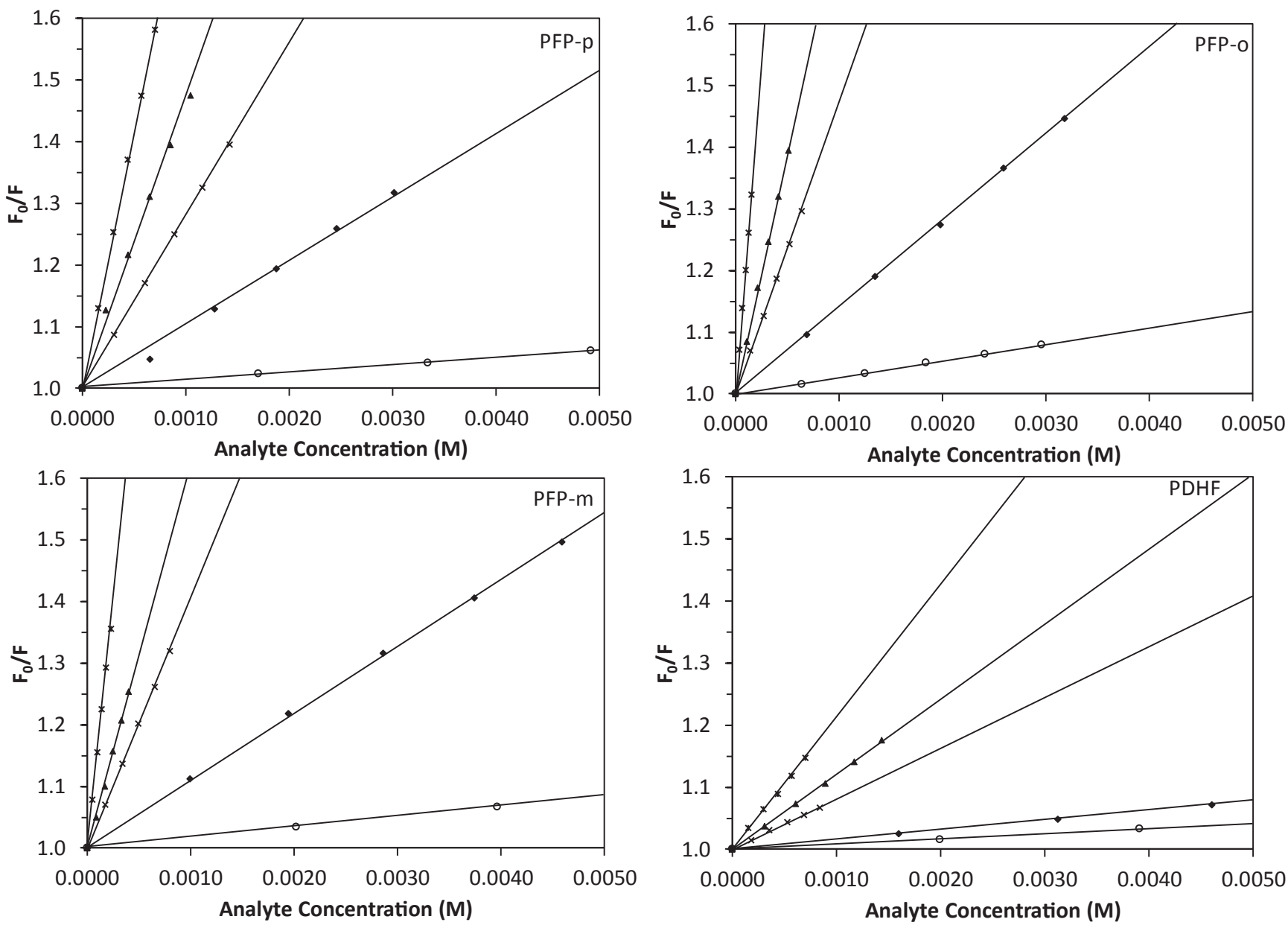

Fig. 3. Stern-Volmer Quenching of PFP-p, PFP-m, PFP-o and PDHF reference material with DNB $(*)$, DNT $(\boldsymbol{\Delta})$, pNT $(\times)$, BP $(\diamond)$ and DMNB $(O)$.

Table 2

Summary of the Stern-Volmer constants of the polymers with DNB, DNT, pNT, DMNB and BP. $K_{c}$ and $K_{s}$ represents the collisional and static quenching constant, respectively.

\begin{tabular}{|c|c|c|c|c|c|}
\hline Polymer & $\begin{array}{l}\mathrm{DNB} \\
K_{s v}, \mathrm{M}^{-1} \\
\left(K_{c}, K_{s}\right)\end{array}$ & $\begin{array}{l}\mathrm{DNT} \\
K_{s v}, \mathrm{M}^{-1} \\
\left(K_{c}, K_{s}\right)\end{array}$ & $\begin{array}{l}\mathrm{pNT} \\
K_{s v}, \mathrm{M}^{-1} \\
\left(K_{c}, K_{s}\right)\end{array}$ & $\begin{array}{l}\text { DMNB } \\
K_{s v}, \mathrm{M}^{-1} \\
\left(K_{c}, K_{s}\right)\end{array}$ & $\begin{array}{l}\mathrm{BP} \\
K_{s v}, \mathrm{M}^{-1} \\
\left(K_{c}, K_{s}\right)\end{array}$ \\
\hline PFP-p & $\begin{array}{l}824 \pm 8 \\
(30,794)\end{array}$ & $\begin{array}{l}427 \pm 40 \\
(26,401)\end{array}$ & $\begin{array}{l}272 \pm 7 \\
(19,253)\end{array}$ & $\begin{array}{l}12 \pm 0.5 \\
(7,5)\end{array}$ & $\begin{array}{l}109 \pm 4 \\
(0,109)\end{array}$ \\
\hline PFP-m & $\begin{array}{l}1586 \pm 29 \\
(17,1569)\end{array}$ & $\begin{array}{l}660 \pm 29 \\
(14,646)\end{array}$ & $\begin{array}{l}397 \pm 6 \\
(12,385)\end{array}$ & $\begin{array}{l}16 \pm 1 \\
(4,12)\end{array}$ & $\begin{array}{l}108 \pm 7 \\
(1,107)\end{array}$ \\
\hline PFP-o & $2012 \pm 128$ & $759 \pm 30$ & $457 \pm 11$ & $28 \pm 1$ & $136 \pm 3$ \\
\hline PDHF & $\begin{array}{l}214 \pm 10 \\
(18,196)\end{array}$ & $\begin{array}{l}120 \pm 2 \\
(14,106)\end{array}$ & $\begin{array}{l}78 \pm 12 \\
(13,65)\end{array}$ & $\begin{array}{l}8 \pm 0.5 \\
(5,3)\end{array}$ & $\begin{array}{l}14 \pm 2 \\
(0,14)\end{array}$ \\
\hline
\end{tabular}

Table 3

Ionization potential (I.P.) and electron affinity (E.A.) of the polymers.

\begin{tabular}{lcc}
\hline Polymer & I.P. $(\mathrm{eV})$ & E.A. $(\mathrm{eV})$ \\
\hline PFP-p & -5.84 & -2.52 \\
PFP-m & -5.82 & -2.18 \\
PFP-o & -5.81 & -1.97 \\
PDHF & -5.76 & -2.51 \\
\hline
\end{tabular}

is given by Eq. (1)

$\frac{F_{0}}{F}=1+K_{S V}[Q]$

where $F_{0}$ is the integrated PL intensity in the absence of an analyte, $F$ is the integrated fluorescence intensity in the presence of an analyte, and [Q] is the concentration of the analyte (dilute) [32].

The steady-state quenching data and a summary of the polymers with pNT, DNT, DNB, DMNB and BP are given in Fig. 3 and Table 2. The $K_{S V} S$ measured for PDHF were similar to those reported for PDHF, validating our methodology. [33] The $K_{S V}$ s followed the general trend of $\mathrm{DNB}>\mathrm{DNT}>\mathrm{pNT}>\mathrm{BP}>\mathrm{DMNB}$. These data correlate well with the electron affinities (EA) of the analytes, where lower EA led to higher $K_{S V}$ s. In addition, the $K_{S V}$ s of the PFP polymers followed the trend: PFP$o>$ PFP-m $>$ PFP-p. The electronic structure of the polymers was studied using photoelectron spectroscopy in air (PESA) and the UV-Vis absorption spectrum (Table 3 ). It was found that the ionization potential of the PFP polymers were similar $(-5.81$ to $-5.84 \mathrm{eV})$, while the EA was $-2.52 \mathrm{eV}$ (PFP-p), $-2.18 \mathrm{eV}$ (PFP-m) and $-1.97 \mathrm{eV}$ (PFPo). The overall free energy change $(\Delta G)$ for electron transfer of the PFP polymers correlate with the quenching trend of the PFP polymers. To that end, the larger energy difference between the analyte and polymer resulted in larger Stern-Volmer quenching constants. This trend does not follow that of the PDHF, where the electron affinity of PFP-p and PDHF are similar, while the Stern-Volmer quenching of PFP-p is roughly four times greater than that of PDHF. The Stern-Volmer quenching of DMNB was $28 \pm 1 \mathrm{M}^{-1}$, which is the highest recorded polymer based sensor for DMNB. The main-stream explosive fluorescence quenching sensing optical probes, based on poly(phenyleneethynylene), do not detect DMNB because of the lower electron affinities that limit thermodynamic requirements for photoinduced electron transfer $[6,7]$. The closest DMNB quenching was based on a substituted PFP polymer with $22 \mathrm{M}^{-1}$ [23]. The record quenching of PFP-o is likely due to the higher electron affinity of the polymer [5]. 

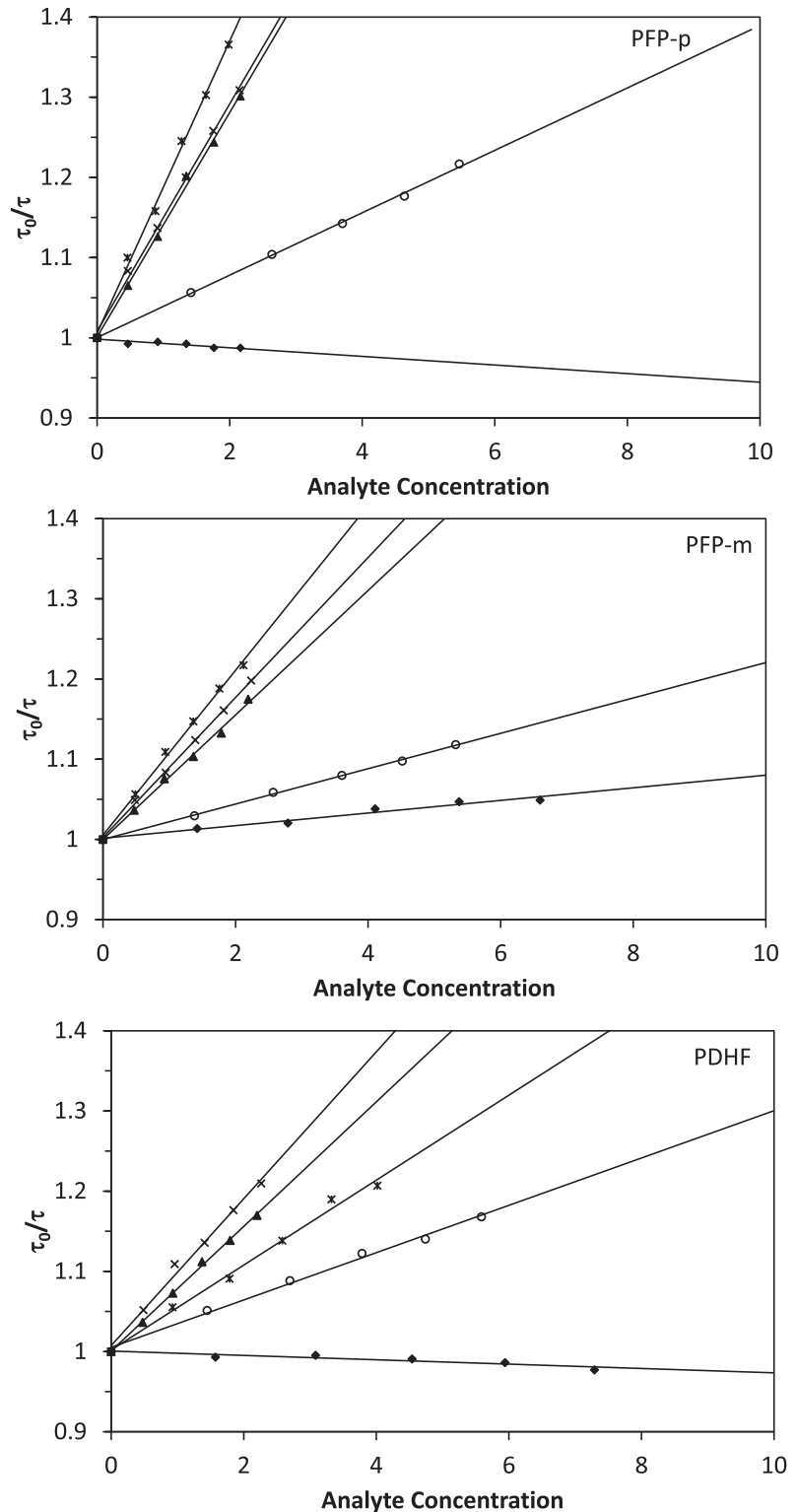

Fig. 4. Time resolved stern-volmer quenching of PFP-p, PFP-m and PDHF with DNB $(*)$, DNT $(\bullet)$, pNT $(\times)$, BP $(\bullet)$ and DMNB $(O)$.

Although this study demonstrated high sensitivity towards DMNB, the selectivity still needs to be improved.

Although steady-state measurements provide information regarding the quenching ability of the polymer, they do not reveal the mechanism of fluorescence quenching [32]. To that end, the steady-state Stern-Volmer constant at low analyte concentrations is the sum of the static $\left(K_{s}\right)$ (the analyte forms a ground state complex with the fluorophore) and collisional $\left(K_{c}\right)$ (the analyte interacts with the photoexcited fluorophore) constants. The collisional quenching constant can therefore be determined using time-resolved measurements, by Eq. (2)

$\frac{\tau_{0}}{\tau}=1+K_{c}[Q]$

where $\tau_{0}$ is the fluorescence lifetime without a quencher, $\tau$ is the fluorescence lifetime with a quencher. The $K_{c}$ and [Q] are the same as defined previously. The static component can therefore be determined by Eq. (3)

$K_{S V}=K_{c}+K_{S}$

Fig. 4 depicts the time-resolved stern-volmer measurements and
Table 2 summarizes the stern-volmer collisional and static quenching constants for the polymers and analytes. In general, the quenching of the polymers by the nitroaromatic analytes was dominated by a static mechanism, while the quenching using DMNB was primarily collisional in nature. This general trend is likely due to differences in intermolecular interactions, where the nitroaromatic analytes are driven by $\pi-\pi$ interactions. Interestingly, this time resolved data suggests that the stronger fluorescence quenching of the PFP polymers over the PDHF is driven by the static interactions between the fluorophore and the quencher. That is, the collisional quenching in all of the polymers is roughly the same (given the same analyte) and the static quenching was the main point of difference, of which the PFP polymers dominated.

To further explore the efficacy of these polymers as sensors, the solid state quenching and recovery of the polymers was investigated (Fig. 5), where the initial intensity was normalised to delineate the effect of interchain interactions. These data were collected from the emission of a polymer thin film to mimic a Nomadics Fido sensing device [34], and described in the supporting information. It was found that all of the films showed photoluminescence quenching after exposing it to PNT, DMNB and BP and the emission intensity recovered after blowing nitrogen over the sample. Upon exposure of the films to an analyte, the photoluminescence of the films rapidly quenched followed by a plateau into steady-state of quenching. The general trend for quenching was PFP-p > PFP-m > PDHF > PFP-o (Table 4), where PFP-p is amongst the most sensitive materials towards PNT. The PDHF films quenched to $80.4 \%$, which is similar to that previously observed for poly(9,9-dioctylfluorene), which benchmarks these results [35]. The trend in the film data can be attributed to a combination of the exergonicity of electron transfer (driven by LUMO-LUMO offsets) and the kinetics of analyte diffusion (driven by the porosity of the polymer film) [22]. These results indicate that the PFP-p is the most porous and the PFP-o is the least porous PFP. To support this theory, AM1 geometry optimization calculations were performed on PFP mimics (Fig. 1) and the estimated free volumes were $14 \AA^{3}$ (PFP-o), $139 \AA^{3}$ (PFP-m) and $>150 \AA^{3}$ (PFP-p). The porosity of the films was previously correlated with the stokes shift of the polymers, which is consistent with this data, because it results in "viscous drag" [23]. The recovery of the photoluminescence by blowing nitrogen on the sample was studied (Table 5) and it was found that the PFP-p, which is best quencher in the thin film, required the longest time to recover to steady-state. This longer recovery time suggests that the analyte is trapped in the polymer film [22].

Fig. 6 depicts the rate of quenching of PFP-m as a function of the analytes. For a given polymer, the general trend of the analyte quenching rate is: PNT $>$ DMNB $>$ BP. The PNT displays the highest quenching rate, which is reasonable since it has the highest vapour pressure $\left(4.89 \times 10^{-2}\right.$ torr $)$ and the free energy of electron transfer is the highest of the three analytes. DMNB and BP have a similar vapor pressure $\left(\sim 1.9 \times 10^{-3}\right.$ torr $)$, yet the DMNB quenches the photoluminescence to a greater extent. From an energetic perspective, the BP should have a larger quenching rate, however it was observed that the DMNB has the highest quenching rate. This difference may be due to stronger electrostatic interactions that limit the speed of analyte diffusion into the polymer film [23]. This is supported by the higher recovery of the original photoluminescence intensity with BP $(88.0 \%$ of the original signal) over the DMNB (72.3\% of the original signal), upon exposing the film to pure nitrogen. In addition, semiempirical (AM1) calculations show that diameter of DMNB is $5.66 \AA$ while the diameter $\mathrm{BP}$ is $6.76 \AA$. Therefore, an additional contributor to the DMNB quenching rate may be because the analyte is smaller allowing it to penetrate the polymer film faster.

\section{Conclusion}

Highly luminescent PFP based polymers were prepared and are 

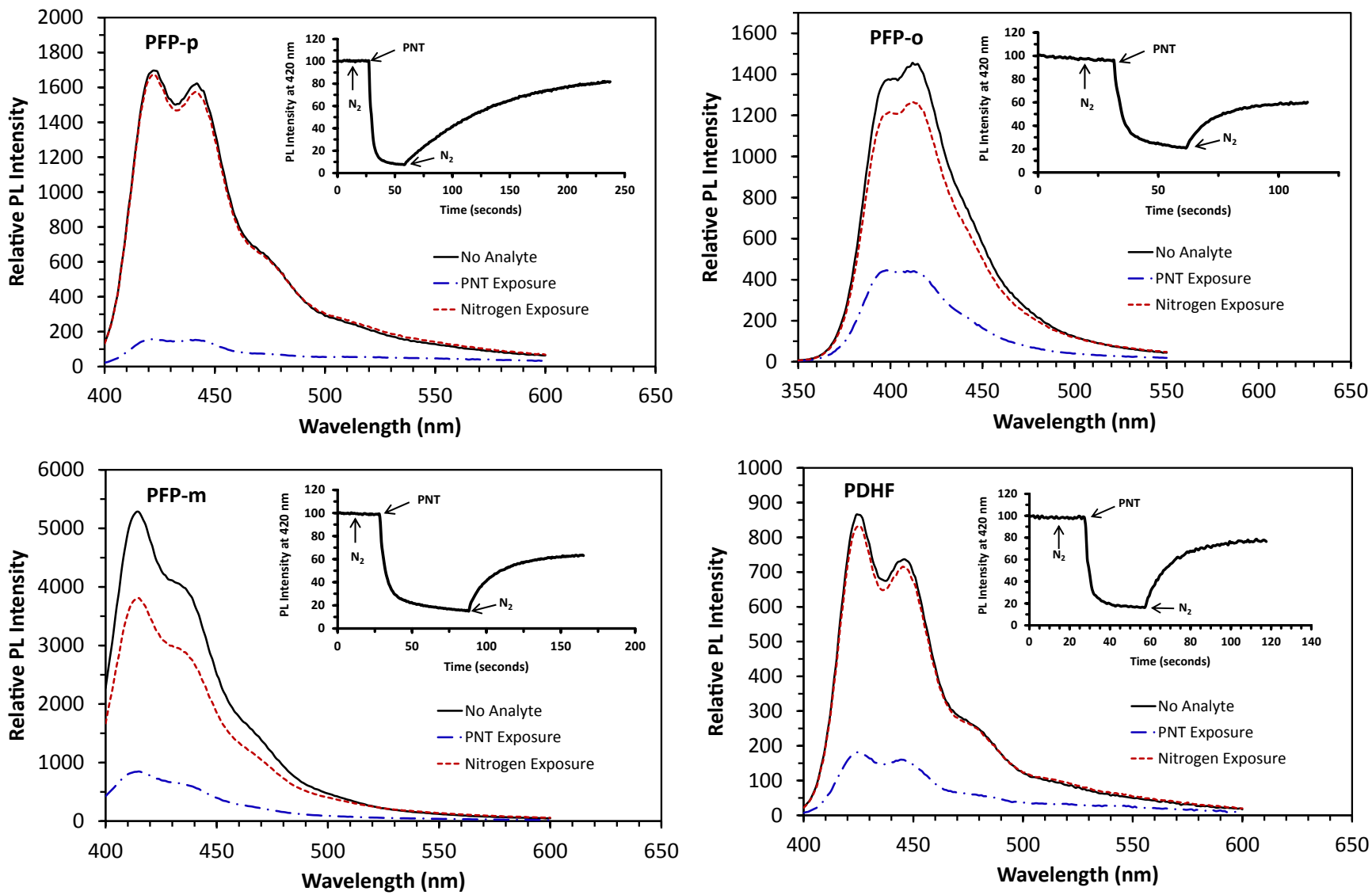

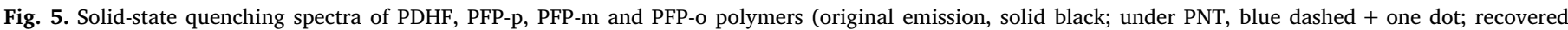

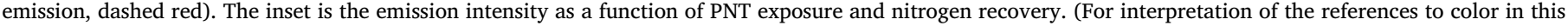
figure legend, the reader is referred to the web version of this article.)

Table 4

Solid state quenching using PNT and DMNB. Values and errors are calculated based on an average of 5 measurements.

\begin{tabular}{|c|c|c|c|c|c|}
\hline Analyte & $P_{\text {vap }}, 298.17 \mathrm{~K}$ (torr) $[8,23]$ & $\begin{array}{l}\text { PFP-p } \\
\text { Quenching [\%] }\end{array}$ & $\begin{array}{l}\text { PFP-m } \\
\text { Quenching [\%] }\end{array}$ & $\begin{array}{l}\text { PFP-o } \\
\text { Quenching [\%] }\end{array}$ & $\begin{array}{l}\text { PDHF } \\
\text { Quenching [\%] }\end{array}$ \\
\hline PNT & $4.89 \times 10^{-2}$ & $91.4 \pm 1.1$ & $83.1 \pm 0.8$ & $76.8 \pm 2.0$ & $80.4 \pm 1.4$ \\
\hline DMNB & $1.88 \times 10^{-3}$ & $71.5 \pm 0.6$ & $63.6 \pm 1.7$ & $53.3 \pm 3.1$ & $59.6 \pm 1.4$ \\
\hline $\mathrm{BP}$ & $1.93 \times 10^{-3}$ & $63.9 \pm 5.0$ & $49.1 \pm 1.8$ & $50.8 \pm 0.2$ & $39.5 \pm 1.5$ \\
\hline
\end{tabular}

Table 5

Solid state emission intensity recovery to steady-state with pure nitrogen for $180 \mathrm{sec}\left({ }^{\mathrm{a}}\right), 120 \mathrm{sec}\left({ }^{\mathrm{b}}\right), 90 \sec \left({ }^{\mathrm{c}}\right), 60 \mathrm{sec}\left({ }^{\mathrm{d}}\right)$ after exposure to PNT, DMNB and BP.

\begin{tabular}{|c|c|c|c|c|}
\hline Analyte & $\begin{array}{l}\text { PFP-p } \\
\text { Recovery [\%] }\end{array}$ & $\begin{array}{l}\text { PFP-m } \\
\text { Recovery [\%] }\end{array}$ & $\begin{array}{l}\text { PFP-o } \\
\text { Recovery [\%] }\end{array}$ & $\begin{array}{l}\text { PDHF } \\
\text { Recovery }[\%]\end{array}$ \\
\hline PNT & $\begin{array}{l}82.6 \pm 1.9^{\mathrm{a}} \\
(55.3 \pm 3.4)^{\mathrm{d}}\end{array}$ & $\begin{array}{l}64.5 \pm 4.9^{c} \\
(60.0 \pm 5.9)^{d}\end{array}$ & $60.6 \pm 2.51^{\mathrm{d}}$ & $85.3 \pm 0.6^{\mathrm{d}}$ \\
\hline DMNB & $\begin{array}{l}93.4 \pm 1.9^{b} \\
(84.5 \pm 3.5)^{d}\end{array}$ & $72.3 \pm 1.7^{\mathrm{d}}$ & $73.0 \pm 4.51^{\mathrm{d}}$ & $81.1 \pm 1.2^{\mathrm{d}}$ \\
\hline BP & $\begin{array}{l}95.6 \pm 2.2^{\mathrm{b}} \\
(89.2 \pm 4.7)^{\mathrm{d}}\end{array}$ & $88.0 \pm 1.1^{\mathrm{d}}$ & $73.6 \pm 0.21^{\mathrm{d}}$ & $94.5 \pm 1.5^{\mathrm{d}}$ \\
\hline
\end{tabular}

amongst the highest photoluminescence solution and thin film quenchers reported for nitro-aromatic and -aliphatic materials. In solution, it was determined that the driving factors for photoluminescence quenching are the exergonicity of electron transfer and the mechanism of quenching, where the PFP-o had optimal characteristics. In the thin film state, the combined factors of exergonicity of electron transfer and the kinetics of diffusion of the analytes are crucial for the sensing. Our

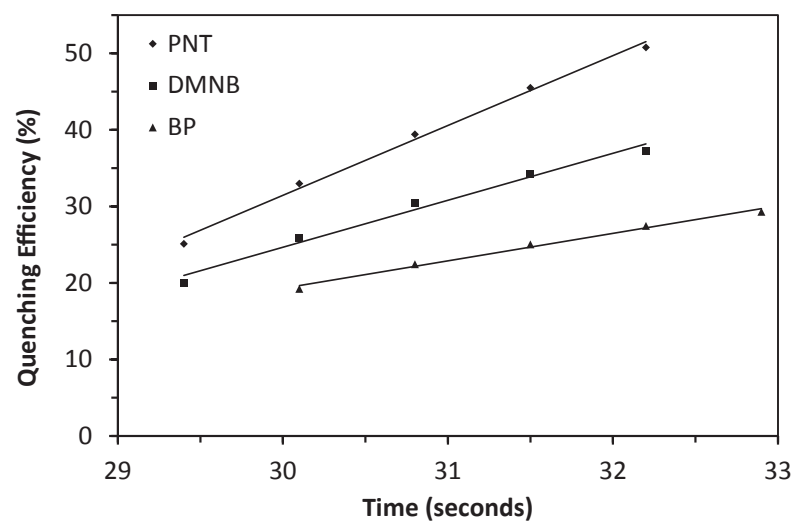

Fig. 6. The quenching rate of PFP-m as a function of PNT ( $\bullet$ ), DMNB ( $\square$ ) and $\mathrm{BP}(\boldsymbol{\Delta})$ analytes.

thin film data suggests that PFP-p had the best compromise between the thermodynamics of quenching and the free molecular volume for high performance sensing. 


\section{Acknowledgments}

G.V. is the recipient of an ARC Australian Research Fellowship (DP 1095404) and thanks the ARC for the LEIF grant (LE150100049). T.D.M.B also acknowledges ARC support through its Discovery program (DP170104477). M.F. and K.K. thank the DAAD for the Research Internships in Science and Engineering (RISE) scholarship and A.K. thanks the Japan Public-Private Partnership Student Study Abroad Program (Tobitate! Young Ambassador Program). The authors acknowledge Shimadzu Scientific Instruments for access to their UV-Vis spectrometer through their "Fostering Science in Education" (FSiE) program.

\section{Data availability statement}

The raw data required to reproduce these findings are available to download from DOI: $10.17632 /$ mffrfcjrwn.1. The processed data required to reproduce these findings are available to download from DOI: $10.17632 / \mathrm{mffrfcj} r w n .1$.

\section{Appendix A. Supplementary material}

Structural characterization spectra of all the polymers, quantum yield of photoluminescence measurement gradients, atomic force microscope images of the polymer films, schematic of solid-state fluorescence quenching system. Supplementary data to this article can be found online at https://doi.org/10.1016/j.eurpolymj.2019.06.040.

\section{References}

[1] G. Vamvounis, N. Sandery, Austr. J. Chem. 68 (2015) 1723-1726.

[2] M.J. Kangas, R.M. Burks, J. Atwater, R.M. Lukowicz, P. Williams, A.E. Holmes, Crit. Rev. Anal. Chem. 47 (2017) 138-153.

[3] A.K.M. Jamil, A.K.M. Jamil, A. Sivanesan, E.L. Izake, G.A. Ayoko, Sens. Actuat. B, Chem. 221, 273-280.

[4] M.Y. Ho, N. D’Souza, P. Migliorato, Anal. Chem. 84 (2012) 4245-4247.

[5] G. Vamvounis, P.E. Shaw, P.L. Burn, J. Mater. Chem. C 1 (2013) 1322-1329.

[6] S.W. Thomas III, G.D. Joly, T.M. Swager, Chem. Rev. (Washington, DC, U.S.) 107 (2007) 1339-1386.

[7] S.J. Toal, W.C. Trogler, J. Mater. Chem. 16 (2006) 2871-2883.

[8] X. Sun, Y. Wang, Y. Lei, Chem. Soc. Rev. 44 (2015) 8019-8061.
[9] D.A. Olley, E.J. Wren, G. Vamvounis, M.J. Fernee, X. Wang, P.L. Burn, P. Meredith, P.E. Shaw, Chem. Mater. 23 (2011) 789-794.

[10] P.S. Hariharan, J. Pitchaimani, V. Madhu, S.P. Anthony, J. Fluoresc. 26 (2016) 395-401.

[11] S. Shanmugaraju, P.S. Mukherjee, Chem. Commun. (Cambridge, U.K.) 51 (2015) 16014-16032.

[12] S. Rochat, T.M. Swager, A.C.S. Appl, Mater. Interfaces 5 (2013) 4488-4502.

[13] H. Nie, Y. Zhao, M. Zhang, Y. Ma, M. Baumgarten, K. Muellen, Chem. Commun. (Cambridge, U.K.) 47 (2011) 1234-1236.

[14] W.-M. Wan, D. Tian, Y.-N. Jing, X.-Y. Zhang, W. Wu, H. Ren, H.-L. Bao, Angew. Chem. 130 (47) (2018) 15736-15742.

[15] T.-P. Huynh, A. Wojnarowicz, A. Kelm, P. Woznicki, P. Borowicz, A. Majka, F. D'Souza, W. Kutner, ACS Sens. 1 (2016) 636-639.

[16] M.A. Ali, S. Shoaee, S. Fan, P.L. Burn, I.R. Gentle, P. Meredith, P.E. Shaw, ChemPhysChem 17 (2016) 3350-3353.

[17] M.A. Ali, Y. Geng, H. Cavaye, P.L. Burn, I.R. Gentle, P. Meredith, P.E. Shaw, Chem. Commun. (Cambridge, U.K.) 51 (2015) 17406-17409.

[18] A.J. Clulow, H. Cavaye, G. Tang, P.E. Shaw, J.J. Cooper-White, P.L. Burn, P. Meredith, J. Mater. Chem. C 3 (2015) 9412-9424.

[19] Y. Geng, M.A. Ali, A.J. Clulow, S. Fan, P.L. Burn, I.R. Gentle, P. Meredith, P.E. Shaw, Nat. Commun. 6 (2015) 8240.

[20] J.S. Kim, B. Cho, S.G. Cho, H. Sohn, Chem. Commun. 52 (2016) 8207-8210.

[21] X.-M. Lin, J.-L. Niu, J. Lin, L. Hu, G. Zhang, Y.-P. Cai, Inorg. Chem. Commun. 72 (2016) 69-72.

[22] J.-S. Yang, T.M. Swager, J. Am. Chem. Soc. 120 (1998) (1873) 11864-11871.

[23] S.W. Thomas III, J.P. Amara, R.E. Bjork, T.M. Swager, Chem. Commun. (Cambridge, U.K.) (2005) 4572-4574.

[24] K. Muellen, J.R. Reynolds, T. Masuda (Eds.), Conjugated Polymers: A Practical Guide to Synthesis. [In: RSC Polym. Chem. Ser., 2014; 9], Royal Society of Chemistry, 2014.

[25] T.J. Gordon, G. Vamvounis, S. Holdcroft, Adv. Mater. (Weinheim, Ger.) 20 (2008) 2486-2490.

[26] G. Vamvounis, S. Holdcroft, Adv. Mater. 16 (2004) 716.

[27] G. Vamvounis, G.L. Schulz, S. Holdcroft, Macromolecules 37 (2004) 8897-8902.

[28] W.H. Melhuish, Quantum efficiencies of flourescence of organic substances: effect of solvent and concentration of the flourescent solute, J. Phys. Chem. 65 (1961) 229-235.

[29] D.F. Eaton, Pure Appl. Chem. 60 (1988) 1107-1114.

[30] R.P. Cox, H.F. Higginbotham, B.A. Graystone, S. Sandanayake, S.J. Langford, T.D.M. Bell, Chem. Phys. Lett. 521 (2012) 59-63.

[31] F.B. Dias, A.L. Maçanita, J.S.D. Melo, H.D. Burrows, R. Güntner, U. Scherf, A.P. Monkman, J. Chem. Phys. 118 (2003) 7119-7126.

[32] J.R. Lakowicz, Principles of Fluorescence Spectroscopy, second ed., Kluwer Academic/Plenum Press, New York, 1999.

[33] H. Cavaye, P.E. Shaw, X. Wang, P.L. Burn, S.-C. Lo, P. Meredith, Macromolecules (Washington, DC, U.S.) 43 (2010) 10253-10261.

[34] C.J. Cumming, C. Aker, M. Fisher, M. Fok, M.J.l. Grone, D. Reust, M.G. Rockley, T.M. Swager, E. Towers, V. Williams, IEEE Trans. Geosci. Rem. Sens. 39 (2001) 1119-1128.

[35] Y. Yang, G.A. Turnbull, I.D.W. Samuel, Adv. Funct. Mater. 20 (2010) 2093-2097. 